\title{
THE FOUR QUALITIES OF LIFE Ordering concepts and measures of the good life
}

\author{
Ruut Veenhoven
}

Journal Of Happiness Studies, 2000, vol 1, pp 1-39

Shortened version reprinted in: McGillivray, M. \& Clarke, M. (eds) 'Understanding Human Well-being', chapter 4, pp 74-100, United Nations University Press, New York, 2006, ISBN 92-808-1130-4

Full version reprinted in: DellaFave, A (ed) 'The Exploration of happiness: Present and future perspectives' Chapter 11 pp 195-226, Springer, Dordrecht, Netherlands, Happiness Studies Book Series 2013, ISBN 978-94-007-5702-8 DOI: 10.1007/978-94-007-5702-8_11

\begin{abstract}
The terms 'quality-of-life', 'wellbeing' and 'happiness' denote different meanings; sometimes they are used as an umbrella term for all of value, and the other times to denote special merits.

This paper is about the specific meanings of the terms. It proposes a classification based on two bi-partitions; between life 'chances' and life 'results', and between 'outer' and 'inner' qualities. Together these dichotomies imply four qualities of life: 1) livability of the environment, 2) life-ability of the individual, 3) external utility of life and 4) inner appreciation of life.

This fourfold matrix is applied in thr ee ways: firstly to place related notions and alternative classifications, secondly to explore substantive meanings in various measures for quality of life and thirdly to find out whether qua lity-of-life can be measured comprehensively. This last question is answered in the negative. Current sum-scores make little sense. The most inclusive summary measure is still how long and happily people live.
\end{abstract}

There are many words that are used to indicate how well we are doing. Some of these signify overall thriving; currently the terms 'quality of life' and 'wellbeing' are used for this purpose, and sometimes the word 'health' ${ }^{1}$. In the past the terms 'happiness' and 'welfare' were more commonly used. There are several problems with these terms.

One problem is that these terms do not have an unequivocal meaning. Sometimes they are used as an umbrella for all that is good, but on other occasions they denote specific merit. For instance: the term 'wellbeing' is used to denote the quality of life-as-a-whole and to evaluate lifeaspects such as dwelling conditions or employment chances. Likewise, the phrase 'quality-of-life' refers in some contexts to the quality of society and in other instances to the happiness of its citizens. There is little view on a consensus on the meaning of these words; the trend is rather to divergence. Over time, connotations tend to become more specific and manifold. Discursive communities tend to develop their own quality-of-life notions.

The second problem is in the connotation of inclusiveness. The use of the words as an umbrella term suggests that there is something as 'overall' quality of life, and that specific merits can be meaningfully added in some wider worth; however that holistic assumption is dubious. Philosophers have never agreed on one final definition of quality-of-life, and in the practice of empirical quality-of-life measurement we see comparisons of apples and pears.

The above problem of many meanings is partly caused by the suggestion of inclusiveness. One of the reasons why the meanings become more specific is that the rhetoric of encompassingnes crumbles when put to practice. The broad overall meaning appears typically unfeasible in measurement and decision making. Hence connotations tend to become more specific and diverse. As result, rhetoric denotation of the overall good requires new terms periodically. New expressions pop up as against more narrow meanings. For instance, in the field 
of healthcare the term 'quality of life' emerged to convey the idea that there is more than mere quantity of survival time. Likewise, the word 'wellbeing' came into use in contrast to sheer economic 'welfare' ${ }^{2}$. Yet, in the long run these new term fall victim to their success. Once they are adopted as a goal for policy, analysts and trend watchers start extracting palpable meanings and make the concepts ever more 'multi-dimensional'.

Obviously, this communicative practice causes much confusion and impedes the development of knowledge in this field. In reaction, there have been many proposals for standard definitions ${ }^{3}$. Unfortunately, this has not really helped. Firstly, such scientific definitions hardly affect the common use of language. Secondly, they add to the confusion, because scholars are not able to agree on one meaning either, for instance, McCall 1975) defines quality-of-life as 'necessary conditions for happiness', while (Terhune 1973) defines it as subjective satisfaction itself. Likewise, Colby (1987) describes wellbeing as 'adaptive potential', whereas Jolles \& Stalpers (1978: 31) define it as 'basic commend to life'. Elsewhere I have listed fifteen definitions of happiness (Veenhoven 1984:16-17). Recently Noll (1999) listed many meanings of quality of life in nations.

Since we cannot really force the use of words, we can better try to clarify their use. We can elucidate the matter by distinguishing different meanings. An analytic tool for this purpose is proposed in this article. First a fourfold classification of qualities of life is presented $(\S 1)$. By means of this taxonomy common terms and distinctions are placed $(\S 2)$. The matrix is then used to chart substantive meanings in common measures of the good life $(\S 3)$. Next the question is raised whether we can meaningfully speak about comprehensive quality of life (§ 4).

\section{GROUPING QUALITIES OF LIFE}

Terms like 'quality of life', 'wellbeing' and 'happiness' denote evaluations. When sorting out what kind of evaluation they aim at, we must establish what thing is evaluated by what standard.

\subsection{Quality of what life?}

In the case of 'quality of life' the object of evaluation is 'life'. Mostly that life is an individual life, the quality of life of a person. Yet the term is also used for aggregates, for instance when we speak about the quality-of-life of women. In that case the term refers usually to the average of individuals. Sometimes the term is used in reference to humanity as a whole. In this context the object of evaluation is mostly the average individual, and the long-term destiny of the species. The evaluation then concerns 'human life', rather than 'human lives'.

The term 'quality of life' does not refer exclusively to human life. It is also used for animals, for instance in discussions about conditions of slaughter cattle. At a higher level of abstraction it is also used for all life. Quality of life is then the condition of the entire ecosystem. Ecological propagandists like this confusion of object matter, because it suggests that protection of endangered species is also good for the individual human.

The terms 'wellbeing' and 'happiness' denote even more varied objects of evaluation, because they are also used in reference to social systems. When speaking about the 'public wellbeing' or the 'happiness of the nation' we often aim at the collective level, how well society functions and maintains itself. Propagandists also exploit this ambiguity, in this case as a means to disguise differences in interest between individuals and society.

In this paper I focus on the quality of individual human lives. As we will see, that is difficult enough. 


\subsection{What quality of life?}

The aim of this paper is to chart the specific meanings denoted by terms like quality-of-life, so we must explore what qualities are implied by the term quality. This requires an exploration of the "varieties of the good".

A classic distinction is between 'objective' and 'subjective' quality of life. The first refers to the degree a life meets explicit standards of the good life, as assessed by an impartial outsider. For instance the result of a medical examination. The latter variant concerns self-appraisals based on implicit criteria, for example, someone's subjective feeling of health. These qualities do not necessarily correspond; someone may be in good health by the criteria of his doctor, but nevertheless feel bad. On the basis of this distinction, Zapf (1984: 25) has proposed a fourfold classification of 'welfare' concepts. When conditions of life score good on objective measures and subjective appreciation of life is positive he speaks of 'wellbeing', when both evaluations are negative he speaks of 'deprivation'. When objective quality is good, but subjective appreciation is negative, the term 'dissonance' is applied, and the combination of bad conditions and positive appreciation is labeled 'adaptation'.

Though elegant, these distinctions have not proven particularly useful. The taxonomy does not explain much. The main reason is that the difference is more in observation than in substance. Objective health-assessment aims at the same qualities as subjective appraisals, though by different means. Further the labeling gives rise to misunderstanding. The word 'objective' suggest indisputable truth, whereas the term 'subjective' is easily interpreted as a matter of arbitrary taste. This suggestion is false, the fact that income can be measured objectively does not mean that its value is beyond question.

\section{Chances and outcomes}

A substantively more relevant distinction is between opportunities for a good life and the good life itself. This is the difference between potentiality and actuality. I refer to this as 'life-chances' ${ }^{4}$ and 'life-results'. Opportunities and outcomes are related, but are certainly not the same. Chances can fail to be realized, due to stupidity or bad luck. Conversely, people sometimes make much of their life in spite of poor opportunities.

This distinction is quite common in the field of public-health research. Pre-conditions for good health, such as adequate nutrition and professional care are seldom mixed up with health itself. Much research is aimed at assessing the relationships between these phenomena; for instance by checking whether common nutritional advice really yields extra years lived in good health.

Yet in social policy discussions means and ends are less well distinguished. For instance, in the Netherlands the term 'wellbeing' is used for both social services, i.e. state pensions, as well as for the expected effects, satisfied citizens. This is not just sloppy thinking, it is also an expression of the ideology that there is quality to be found in the welfare society.

\section{Outer and inner qualities}

A second difference is between 'external' and 'internal' qualities. In the first case the quality is in the environment, in the latter it is in the individual. Lane (1994) made this distinction clear by emphasizing 'quality of persons'. Likewise Musschenga (1994: 182) discerned 'quality of conditions for living'from 'the quality of being human'.

This distinction is also quite commonly made in public health. External pathogens are 
distinguished from inner afflictions, and researchers try to identify the mechanisms by which the former produce the latter and the conditions in which this is more and less likely. Yet again this basic insight is lacking in many social policy discussions. For instance, in the current discourse on city renewal the word 'quality-of-life' is used both for clean streets and feelings of being home in the neighborhood. All the research that found negligible relationships has not changed this use of words.

\subsection{Four qualities of life}

The combination of these two dichotomies yields a fourfold matrix. This classification is presented in scheme 1. The distinction between chances and results is presented vertically, the difference between outer and inner qualities horizontally.

\section{Scheme 1}

Four qualities of life

\begin{tabular}{|c|c|c|}
\hline & Outer qualities & Inner qualities \\
\hline Life chances & Livability of environment & Life-ability of the person \\
\hline \multirow{2}{*}{ Life results } & Utility of life & Appreciation of life \\
\hline
\end{tabular}

\subsubsection{Two kinds of life chances}

In the upper half of the scheme we see two variants of potential quality of life, with next to the outer opportunities in one's environment, the inner capacities to exploit these. The environmental chances can be denoted by the term livability, the personal capacities with the word life-ability. This difference is not new. In sociology the distinction between 'social capital' and 'psychological capital' is sometimes used in this context. In the psychology of stress the difference is labeled negatively in terms of 'burden' and 'bearing power'.

\section{Livability of the environment}

The left top quadrant denotes the meaning of good living conditions. Often the terms 'quality-oflife' and 'wellbeing' are used in this particular meaning, especially in the writings of ecologists and sociologists. Economists sometimes use the term 'welfare' for this meaning. Another term is 'level of living'

'Livability' is a better word, because it refers explicitly to a characteristic of the 
environment and does not have the limited connotation of material conditions. One could also speak of the 'habitability' of an environment, though that term is also used for the quality of housing in particular. Elsewhere I have explored that concept of livability in more detail (Veenhoven 1996:7-9).

\section{Life-ability of the person}

The right top quadrant denotes inner life-chances. That is: how well we are equipped to cope with the problems of life. This aspect of the good life is also known by different names. The words 'quality of life' and 'wellbeing' are also used to denote this specific meaning, especially by doctors and psychologists. There are more names however. In biology the phenomenon is referred to as 'adaptive potential'. On other occasions it is denoted by the medical term 'health', in the medium variant of the word ${ }^{5}$, or by psychological terms such as 'efficacy' or 'potency'. Sen (1992) calls this quality of life variant 'capability'. I prefer the simple term 'life-ability', which contrasts elegantly with 'livability'.

\subsubsection{Two kinds of life-results}

The lower half of the scheme is about the quality of life with respect to its outcomes. These outcomes can be judged by their value for one's environment and value for oneself. The external worth of a life is denoted by the term 'utility of life'. The inner valuation of it is called 'appreciation of life'. These matters are of course related. Knowing that one's life is useful will typically add to the appreciation of it. Yet not all useful lives are happy lives and not every good-for-nothing really cares. This difference has been elaborated in discussions on utilitaristic moral philosophy, which praises happiness as the highest good. Adversaries of that view hold that there is more worth to life than just pleasures and pains. Mill (1863) summarized that position in his famous statement that he preferred an unhappy Socrates to a happy fool.

\section{Utility of life}

The left bottom quadrant represents the notion that a good life must be good for something more than itself. This presumes some higher values. There is no current generic for these external turnouts of life. Gerson (1976: 795) referred to these kinds as 'transcendental' conceptions of quality of life. Another appellation is 'meaning of life', which then denotes 'true' significance instead of mere subjective sense of meaning. I prefer the more simple 'utility of life', admitting that this label may also give rise to misunderstanding ${ }^{6}$. Be aware that this external utility does not require inner awareness. A person's life may be useful from some viewpoint, without them knowing $^{7}$.

\section{Appreciation of life}

Finally, the bottom right quadrant represents the inner outcomes of life. That is the quality in the eye of the beholder. As we deal with conscious humans this quality boils down to subjective appreciation of life. This is commonly referred to by terms such as 'subjective wellbeing', 'lifesatisfaction' and 'happiness' in a limited sense of the word ${ }^{8}$. Life has more of this quality, the more and the longer it is enjoyed. In fairy tales this combination of intensity and duration is denoted with the phrase 'they lived long and happily'.

\subsection{Similar distinctions in other disciplines}

This categorizing can be clarified using some analogies. Similar conceptual distinctions can be found in biology, economics and systems theory. 


\section{Biology}

In evolutionary biology, external living conditions are referred to as the 'biotope' or 'habitat'. A biotope can be more or less suitable (livable) for a species, depending on e.g. availability of food, shelter and competition. Inner capabilities to survive in that environment are called 'fitness'. This latter term acknowledges that capabilities must meet (fit) environmental demand. Unlike moral philosophers, biologists see no quality in capacity that is not functional.

This chance-constellation is seen to result in 'adaptation', and good adaptation is seen to manifest in 'survival'. As evolutionary biologists focus on species rather than on individual specimen, they mean mostly survival of the species. Hence the success of an individual life is mainly judged by its procreation. Once genes have been passed on, the external utility of an individual life is often little more than that of a prey for another creature.

At the individual level good adaptation is seen to manifest in a relatively long life. An organism that perishes prematurely has adapted less well than the one that completed its programmed lifetime. In higher animals, good adaptation also reflects in hedonic experience. Continuous stress and pain is indicative of poor adaptation. As humans are capable of reflecting on their experiences, their feelings of pleasure and pain condense into overall appraisals of happiness. So, human adaptation manifests in long and happy living. Though inner experience is no great issue in biology, this idea is implied in its logic. These biological concepts are summarized in scheme $2 \mathrm{a}$.

\section{Scheme $2 a$}

Comparable concepts in biology

\begin{tabular}{|c|c|c|}
\hline & Outer quality & Inner quality \\
\hline Life chances & Biotope & Fitness \\
\hline Life results & Adaptation: \\
& Continuation of species & $\begin{array}{c}\text { Adaptation: } \\
\text { Long and happy life }\end{array}$ \\
\hline
\end{tabular}

\section{Economics}

In economic thought, the equivalent of the life situation for a person is the market for a business. As a person's situation can be more or less livable, so a market can be more or less exploitable. Successful exploitation of market chances requires 'capital', both financial capital to buy materials and machinery and human capital to run the enterprise. Capital is, for a business, what 'capability' is for an individual. These chances can result in economic success. At the business level this is 'profit', which is analogous to an individual's 'appreciation of life' ${ }^{9}$. At the societal 
level business success can contribute to public wealth, and thereby to social and cultural evolution. This is analogous to an individual's 'utility of life'.

Scheme $2 b$

Comparable concepts in economics

\begin{tabular}{|c|c|c|}
\hline & Outer quality & Inner quality \\
\hline Chances & Market & Capital \\
\hline Results & Public wealth & Private profit \\
\hline
\end{tabular}

System theory

Finally there is also an analogy with system theory, the main concepts of which are 'input', 'throughput' and 'output'. In this thinking, 'input' is the system's environment, in particular the things the system can extract from that environment. Without any input, the system cannot function and perishes. The richer the input is, the better, and the more in line it is with the systems needs. Good input for a system is what a 'livable' situation is for an individual.

System theory acknowledges that environmental supply alone is not enough to keep the system going. The system must actively process the input. This is commonly called 'throughput'. The capacity to do this job is an inner quality of the system. This system capability is analogous to 'life-ability' of a person.

In system theory the term 'output' denotes all results of system activity. Part of that output is external and serves as input for other systems. This is analogous to the 'utility of life'. Another part of the output is used for system preservation. This concerns inner effects and belongs to the right bottom quadrant.

For an individual, system maintenance involves first of all survival. Since biological organisms cannot live forever, that boils down to living a relatively long life. In higher organisms, system-preservation systems also manifests in how well they feel. As noted above, affective appraisals function as feedback mechanisms in higher animals, positive affect typically signaling that things are going well. In humans these appraisals are condensed into estimates of overall 'happiness'. So, in humans, good output manifests at the individual level in long and happy living. 


\section{Scheme $2 c$}

Comparable concepts in system theory

\begin{tabular}{|c|c|c|}
\hline & Outer quality & Inner quality \\
\hline Chances & Input & Throughput \\
\hline Results & $\begin{array}{c}\text { Output: } \\
\text { External effects } \\
\text { (input for other systems) }\end{array}$ & $\begin{array}{c}\text { Output: } \\
\text { Feedback }\end{array}$ \\
\hline
\end{tabular}

\section{ORDERING CONCEPTS OF THE GOOD LIFE}

With the help of this matrix we can now place the various notions about the good life. I will start with an overview of concepts that neatly fit the quality quadrants $(\S 2.1)$. Next I will mention some common notions that overlap quadrants $(\S 2.2)$. Finally I confront the matrix with some other classifications of qualities of life $(\S 2.3)$

\subsection{Meanings within quality-quadrants}

Most discussions of the good life deal with more specific values than the four qualities of life discerned here. Within each is the quadrants there is a myriad of sub-meanings, most of which are known under different names. It would need a voluminous book to record all the terms and meanings used in the literature. I present some of the main variants below. The main points are summarized in scheme 3.

\subsubsection{Aspects of livability}

Livability is an umbrella term for the various qualities of the environment, which seem relevant for meeting human needs. In rhetoric use the word refers mostly to specific kinds of qualities which typically root in some broader perception of the good society. The circumstantial qualities that are emphasized differ widely across contexts and disciplines.

Ecologists see livability in the natural environment and describe it in terms of pollution, global warming and degradation of nature. Currently, they associate livability typically with 'preservation'. City planners see livability in the built environment and associate it with sewer systems, traffic jams and ghetto formation. Here the good life is seen as a fruit of human intervention.

In the sociological view society is central. Firstly, livability is associated with the quality 
of society as a whole. Classic concepts of the 'good society' stress material welfare and social equality, sometimes equating the concept more or less with the welfare state. Current notions emphasize close networks, strong norms and active voluntary associations. The reverse of that livability concept is 'social fragmentation'. Secondly, livability is seen in one's position in society. For long the emphasis was on 'under-class' but currently attentions shifts to 'outerclass'. The corresponding antonyms are 'deprivation' and 'exclusion'.

\subsubsection{Kinds of life-ability}

The most common depiction of this quality of life is absence of functional defects. This is 'health' in the limited sense, sometimes referred to as 'negative health'. In this context doctors focus on unimpaired functioning of the body while psychologists stress the absence of mental defects. In their language, quality of life and wellbeing are often synonymous with mental health. This use of words presupposes a 'normal' level of functioning. Good quality of life is the body or mind working as designed. This is the common meaning used in curative care.

Next to absence of disease one can consider excellence of function. This is referred to as 'positive health' and associated with energy and resilience. Psychological concepts of positive mental health involve also autonomy, reality control, creativity and inner synergy of traits and strivings. A new term in this context is 'emotional intelligence'. Though originally meant for specific mental skills, this term has come to denote a broad range of mental capabilities. This broader definition is the favorite in the training professions.

A further step is to evaluate capability in a developmental perspective and to include acquisition of new skills for living. This is commonly denoted by the term 'self-actualization', from this point of view a middle-aged man is not 'well' if he behaves like an adolescent, even if he functions with problems at this level. This quality concept is also currently used in the training professions.

Lastly, the term 'art of living' denotes special life-abilities; in most contexts this quality is distinguished from mental health and sometimes even attributed to slightly disturbed persons. Art of living is associated with refined tastes, an ability to enjoy life and an original style of life.

\subsubsection{Criteria for utility of life}

When evaluating the external effects of a life, one can consider its functionality for the environment. In this context, doctors stress how essential a patient's life is to its intimates. The life of a mother with young children is valued as higher than the life of a woman of the same age without children. Likewise, indispensability at the workplace figures in medical quality of life notions.

At a higher level, quality of life is seen in contributions to society. Historians see quality in the addition an individual can make to human culture, and rate for example the lives of great inventors higher than those of anonymous peasants. Moralists see quality in the preservation of the moral order, and would deem the life of a saint to be better than that of a sinner.

In this vein the quality of a life is also linked to effects on the ecosystem. Ecologists see more quality in a life lived in a 'sustainable' manner than in the life of a polluter. In a broader view, the utility of life can be seen in its consequences for long term evolution. As an individual's life can have many environmental effects, the number of such utilities is almost infinite.

Apart from its functional utility, life is also judged on its moral or esthetic value. Returning to Mill's statement that he preferred an unhappy Socrates to a happy fool. Mill did not say this just because Socrates was a philosopher whose words have come down to us; it was also because he admired Socrates as an outstanding human being. Likewise, most of us would attribute more 
quality to the life of Florence Nightingale than to that of a drunk, even if it appeared that her good works had a negative result in the end. In classic moral philosophy this is called 'virtuous living', and is often presented as the essence of 'true happiness'.

This concept of exemplaric utility sometimes merges with notions of inner life-ability, in particular in the case of self-actualization. Self-development is deemed good, even if it might complicate life. In some philosophies of life, reaching a state of enlightenment is more important than departing from it.

This quality criterion is external; the individuals need not be aware of their perfection or may actually despise it. It is an outsider that appraises the quality of the individual's life on the basis of an external criterion. In religious thinking such a judgement is made by God on the basis of eternal truth, in post-modern thought it narrated by self-proclaimed experts on the basis of local conviction.

Clearly, the utility of life is not easy to grasp the criteria and those who would judge, are multifarious. Later we will see that this prohibits comprehensive measurement of this quality of life. This quadrant is typically the playground of philosophers.

\subsubsection{Appreciation of life}

Humans are capable of evaluating their life in different ways. As already noted, we have in common with all higher animals that we can appraise our situation affectively. We feel good or bad about particular things and our mood level signals overall adaptation. As in animals these affective appraisals are automatic, but unlike other animals it is known that humans can reflect on that experience. We have an idea of how we have felt over the last year, while a cat does not. Humans can also judge life cognitively by comparing life as it is with notions of how it should be.

Most human evaluations are based on both sources of information, that is: intuitive affective appraisal and cognitively guided evaluation. The mix depends mainly on the object. Tangible things such as our income are typically evaluated by comparison; intangible matters such as sexual attractiveness are evaluated by how it feels. This dual evaluation system probably makes the human experiential repertoire richer than that of our fellow-creatures.

In evaluating our life we typically summarize this rich experience in overall appraisals. For instance we appreciate several domains of life. When asked how we feel about our work or own marriage we will mostly have an opinion. Likewise, most people form ideas about separate qualities of their life, for instance how challenging their life is and whether there is any meaning in it. Such judgments are made in different time-perspectives, in the past, the present and in the future. As the future is less palpable than the past and the present, hopes and fears depend more on affective inclination than on cognitive calculation.

Mostly such judgments are not very salient in our consciousness. Now and then they pop to mind spontaneously, and they can be recalled and refreshed when needed. Sometimes however, life-appraisals develop into pervasive mental syndromes such as depression or ennui.

Next to aspects of life we also evaluate life-as-a-whole. Jeremy Bentham (1789) thought of this form of evaluation as a type of 'mental calculus', and currently most scholars in the field also see it as a cognitive operation. For instance Andrews \& Withey (1976) suggest that individuals compute a weighed average of earlier life-aspect evaluations, while Michalos' (1985) multiple discrepancy theory presumes comparisons of life as it is with various 
standards of how it should be. Many philosophers see it as an estimate of success in realizing one's life-plan (f.e. Nordenfelt 1989).

Yet there are good reasons to assume that overall life-satisfaction is mostly inferred from affective experience (Veenhoven 1997: 59-61). One reason is that life-as-a-whole is not a suitable object for calculative evaluation. Life has many aspects and there is usually not one clear-cut ideal model to compare with. Another reason seems to be that affective signals tend to dominate, seemingly cognitive appraisals are often instigated by affective cues (Zajonc 1980). This fits the theory that the affective system is the older in evolutionary terms, and that cognition works as an addition to that navigation system rather than a replacement.

This issue has important consequences for the significance of subjective appreciation of life as a criterion for quality-of-life. If appreciation is a matter of mere comparison with arbitrary standards, there is little of value in a positive evaluation; dissatisfaction is then an indication of high demands. If, however, happiness signals the degree to which innate needs are met, life-satisfaction denotes how well we thrive.

Whatever the method of assessment, the fact that we are able to come to an overall evaluation of life is quite important. Later on we will see that this is the only basis for encompassing judgments of the quality of life.

\section{Scheme 3}

Some sub-meaning within quality-quadrants

\begin{tabular}{|c|c|c|}
\hline & Outer qualities & Inner qualities \\
\hline Life chances & $\begin{array}{l}\text { Livability of environment } \\
\text { Ecological } \\
\text { e.g. moderate climate, clean air, spacious } \\
\text { housing, } \\
\text { Social } \\
\text { e.g.. freedom, equality and brotherhood } \\
\text { Economical } \\
\text { e.g. wealthy nation, generous social } \\
\text { security, smooth economic development } \\
\text { Cultural } \\
\text { e.g. flourishing of arts and sciences, mass } \\
\text { education } \\
\text { Etc... }\end{array}$ & $\begin{array}{l}\text { Life-ability of the person } \\
\text { Physical health } \\
\text { negative: free of disease } \\
\text { positive: energetic, resilient } \\
\text { - Mental health } \\
\text { negative: free of mental defects } \\
\text { positive: autonomous, creative } \\
\text { - Knowledge } \\
\text { e.g. literacy, schooling } \\
\text { - Skills } \\
\text { e.g. intelligence, manners } \\
\text { - Art of living } \\
\text { e.g. varied lifestyle, differentiated taste } \\
\text { Etc.... }\end{array}$ \\
\hline Life results & $\begin{array}{l}\text { Objective utility of life } \\
\text { External utility } \\
\text { e.g. For intimates: rearing children, care } \\
\text { for friends } \\
\text { e.g. For society: being a good citizen } \\
\text { e.g. for mankind: leaving an invention } \\
\text { Moral perfection } \\
\text { e.g. authenticity, compassion, originality } \\
\text { - } \\
\text { Etc... }\end{array}$ & $\begin{array}{l}\text { Subjective appreciation of life } \\
\text { appraisal of life-aspects } \\
\text { e.g. Satisfaction with job } \\
\text { e.g. satisfaction with variety } \\
\text { Prevailing moods } \\
\text { e.g. Depression, ennui } \\
\text { e.g. zest } \\
\text { Overall appraisals } \\
\text { Affective: general mood-level } \\
\text { Cognitive: contentment with life }\end{array}$ \\
\hline
\end{tabular}




\subsection{Meanings in broader words for the good life}

With the help of the taxonomy given above, we can now clarify the substantive meaning of several further terms. This enumeration is not exhaustive; the goal is to illustrate this approach

\section{Adjustment}

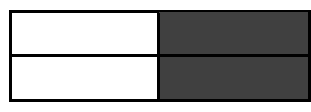

This term came into use in the 1960's, in particular in gerontologic studies of 'adjustment to old age', and was used interchangeably with 'adaptation. These words were soon ousted by phrases like 'morale', 'psychological wellbeing' and 'life-satisfaction'. The term referred to personal qualities; hence it belongs in the right side of our matrix. Adjustment denotes how well a person deals with life, and refers both to equipment and success. Hence the concept does not fit one quadrant, but covers both life-abilities and life-appraisals. In the diagram this is indicated by two equally dark quadrants.

\section{Art of living}

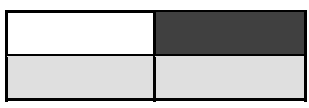

The expression 'art of living' refers, first of all, to a person's life-ability and therefore belongs in the right-top quadrant. As noted above, the term depicts mostly the quality of a life-style, typically refined Epicurianism, but sometimes the wisdom of simple living is also valued as artistry. This main meaning is reflected in the dark colored quadrant. Yet the term bears other connotations, capacity is often associated with its intended results, hence art of living tends to be equated with happiness, or at least with sensorial gratification. Further, the life of a life-artist is sometimes valued as a piece of art in itself, which has some external utility. For instance, we see quality in the life of Casanova, even though the man himself seems not to have been particularly happy. The adjunct connotations of the word are indicated in gray.

\section{Deprivation}

The word 'deprivation' refers to shortfall of something. When used in an absolute sense it means failure to meet basic human needs, when used in a relative sense it means being less well off than others. The word is typically used in the latter meaning, while suggesting the former. Current specifications of this notion are 'poverty' and 'social exclusion'.

In most contexts the lack is in external conditions of life, and concerns access to income, power and prestige. In social policy this kind of deprivation is typically met with redistribution of these scarce resources. This main meaning belongs in the livability quadrant.

Sometimes the word also refers to deficiency in ones capacity to stand up for oneself. The political cure for this problem is 'empowerment', common ingredients of which are general education, political training and boosting of self-esteem. The latter adjunct definition belongs in the life-ability quadrant.

Usually these conditions are associated with the expected outcome for individuals, that is with 'happiness'. Hence measures of deprivation often include items on dissatisfaction, depression and suicidal ideation. Enjoyment of life in spite of objective deprivation is seen as an anomaly. As we have seen above, in Zapf's conceptual schema it is labeled 'resignation' 


\section{Happiness}

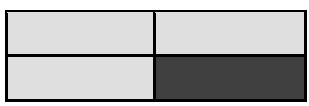

I will now continue the earlier discussion on the connotations of the word happiness. As noted in the introduction of this paper, the word has often been used as a generic for all worth and is in this sense synonymous with comprehensive 'quality-of-life' or 'wellbeing'. In the later discussion of inner outcome notions, the word came back in two, more narrow forms, first as a label for all subjective appraisals of life, and second, as the overall evaluation of life as a whole. The latter use of the word is most common in present day 'social indicators research'.

Beyond this main denotation of the word, there are still further adjunctive uses of the term. This appears for example in the well known definition of happiness given by Tatarkiewicz (1975:16) "....justified satisfaction with life". The adjective 'justified' means that mere enjoyment of life does not constitute (true) happiness if it occurs in abjective situations, for example a prisoner cannot be really happy. Similarly Tatarkiewicz would not call someone happy when the evaluation is based on misperception, such as in the case of the simpleton 'happy Hans', or when the enjoyment is derived from a useless life.

\subsection{Difference with other classifications of qualities of life}

This is of course not the first attempt to chart concepts of the good life. A few examples will show how this matrix differs from other taxonomies.

Philosopher Dan Brock (1993: 268-275) also tried to grasp ".the broadest conception of .. what makes a life go best". He distinguishes three main concepts: 1) the degree to which life fits current values and ideals, 2) the degree to which life fits the individuals preferences, and 3) the degree to which the individual enjoys life subjectively. He denotes the first concept as 'objective' and the other two as 'subjective'. Brock insists on the difference between satisfaction of preferences (contentment in my terminology) and hedonic enjoyment (mood level).

These meanings are plotted in scheme 3a. The difference is not so much in the appreciation quadrant, but in the other three. Brock's classification is less differentiated, and shovels all the objective meanings into one heap. As he is mainly concerned with health care, one can imagine that he leaves out societal livability. Yet he does not distinguish either between 'capability for life' and 'utility of life', though this distinction is quite relevant for medical decisions.

Sandoe (1999) proposes a similar classification, which also separates realization of preferences and hedonic experience. The difference is that his 'objective' qualities limit to the development of potentials. His refers to that quality as 'Perfectionism'. This is what I referred to as 'self-actualization'. In the matrix it is a part of the life-ability quadrant. 
Scheme $3 a$

Fit with Brock's classification

\begin{tabular}{|c|c|c|}
\hline & Outer quality & Inner quality \\
\hline Chances & $\begin{array}{r}\text { Objective quality } \\
\text { Life meets normative ideals }\end{array}$ \\
\cline { 1 - 1 } Results & $\begin{array}{c}\text { Subjective quality } \\
\text { life meets preferences } \\
\text { life is enjoyed }\end{array}$ \\
\hline
\end{tabular}

Storrs McCall (1975) also distinguishes two main concepts of quality of life. Next to happiness itself he emphasizes conditions for happiness. In his view life has also quality if the necessary social conditions are available, even if an individual fails to exploit these chances or opts not to use them. Happiness is seen to result from need-gratification, and hence the necessary conditions are linked to basic human needs. In this concept human nature is the mayor yardstick, and not normative ideals. Consequently, the utility quadrant remains empty in this case. McCall does not distinguish between external and internal requisites, thus the two top quadrants are merged.

Scheme $3 b$

Fit with McCall's classification

\begin{tabular}{|c|l|c|}
\hline & \multicolumn{1}{|c|}{ Outer quality } & Inner quality \\
\hline Chances & $\begin{array}{l}\text { Conditions for happiness } \\
\bullet \quad \text { General happiness requisites } \\
\text { Idiosyncratic happiness requisites }\end{array}$ \\
\hline Results & \multicolumn{2}{|c|}{ Happiness } \\
\hline
\end{tabular}




\section{ORDERING MEASURES OF THE GOOD LIFE}

The last decades have witnessed a surge in empirical research on the good life, in particular in the fields of social indicators research and medical quality of life assessment. This has produced a wealth of measures. Testbanks contain hundreds of them. See for instance Cummins (1994), Spilker (1996) and Veenhoven (2000a).

Most of these measures are 'multi-dimensional' and are used to assess different qualities of life. Typically, the scores on the different qualities are presented separately in a 'quality-of-life profile'. Often they are also summed in a 'quality-of-life score'. Next, there are also 'uni-dimensional' measures, which focus on one specific quality. Such single qualities are often measured by single questions. For instance, the condition of cancer patients is also measured by simply asking them where they stand between the best and worst they have ever experienced (Bernheim \& Buyse 1983).

A lively discussion about the pros and cons of these measures is still going on. This discussion is dominated by psychometricians, who focus very much on factor loadings, reliability issues and inter-test correlations. There is less attention for matters of substance, so there is no clear answer to the question of what these measures actually measure. One of the reasons for this deficiency is a lack of a clear taxonomy of the qualities of life.

Now we have a classification of meanings we can give it another try. Below I will first outline which of these qualities figure in measures that claim to cover the good of life inclusively $(\S 3.1)$. Next I will explore whether there are measures that fit one of the four qualities of life separately $(\S 3.2)$.

\subsection{Meanings in comprehensive measures of quality of life}

As there are so many measures of the good life, I cannot review them all. Four examples must suffice to illustrate the approach. The examples are taken from different research fields: a) medical 'quality of life' research, b) psychological 'wellbeing' research, c) sociologically oriented research on 'welfare' and d) socio-economic studies of national 'development'.

\subsubsection{Example of a medical quality of life index}

One of the most common measures in medical quality of life research is the 'SF-36 Health Survey' (Ware 1996). It is a questionnaire on the following topics:

- physical limitations in daily chores (10 items)

- physical limitations to work performance (4 items)

- bodily pain (2 items)

- perceived general health (6 items)

- vitality (4 items) 
- physical and/or emotional limitations to social functioning (2 items)

- emotional limitations to work performance (3 items)

- self characterizations as nervous (1item)

- recent enjoyment of life (4 items)

Ratings on the first four topics are grouped in a 'Physical Component Subscore', ratings on the last four topics in a 'Mental Component Subscore'. These components are added into a 'Quality of life Total score'.

Most elements of this scale refer to performance potential and belong in the life-ability quadrant right top. This will be no surprise, since the scale is aimed explicitly at health. Still, some of the items concern outcomes rather than potency, in particular the items on recent enjoyment of life (last on the list). Pain and bad feelings are typically the result of health defects. Happiness is clearly also an outcome. As a proper health measure, the SF-36 does not involve outer qualities. So the left quadrants in scheme 4 a remain empty.

Several other medical measures of quality of life do involve items about environmental conditions that belong in the livability quadrant. For instance, the 'Quality Of Life Interview Schedule' by Ouelette-Kuntz (1990) is about availability of services for handicapped persons. In this supply centered measure of the good life, life is better the more services are offered and the more greedily they are used. Likewise, the Quality of Life Index for cancer patients (Spitzer et al 1981) lists support by family and friends as a quality criterion. Some medical indexes also include outer effects that belong to the utility quadrant. Some typical items are, continuation of work tasks and support provided to intimates and fellow patients.

\section{Scheme $4 a$}

Meanings measured by Ware's SF 36 Health Survey

\begin{tabular}{|c|c|c|}
\hline & Outer quality & Inner quality \\
\hline Life-chances & & $\begin{array}{c}\text { No limitations to work and } \\
\text { social functioning } \\
\text { Not nervous } \\
\text { Energetic }\end{array}$ \\
& General health good \\
\hline Life results & & No pain \\
& & No bad feelings \\
& Happy person \\
\hline
\end{tabular}

\subsubsection{Example of a psychological wellbeing scale}

Cummins (1993) sees quality of life (QOL) as an aggregate of 'objective' and 'subjective' components. Each of these components is divided into the following seven domains:

- material wellbeing: measured by income, quality of house and possessions.

- health: measured by number of disabilities and medical consumption. 
- productivity: measured by activities in work, education and leisure

- intimacy: contacts with close friends, availability of support

- safety: perceived safety of home, quality of sleep, worrying

- place in community: social activities, responsibilities, being asked for advise

- emotional wellbeing: opportunity to do/have things wanted, enjoyment of life

Overall QOL is measured using a points system, objective QOL using simple scores, subjective QOL using satisfaction with domains weighted by perceived importance of domains. Finally the scores on objective and subjective QOL are added.

The objective scores of this list represent typically life-chances, though the safety items are subjective appraisals. This item is therefore placed between brackets in scheme 4b. Most of the items concern environmental chances and are placed in the livability quadrant left top. Two items concern inner capabilities and are placed in the life-ability quadrant top right.

The subjective scores all refer to how the individual appreciates these aspects of life, and belong in the enjoyment quadrant bottom right. The Cummins scale has no items on overall satisfaction with life. The logic of his system produces the somewhat peculiar item 'How satisfied are you with your own happiness?' (item 7 SQOL).

The bottom left quadrant remains empty in this interpretation; however, some of the life-chance items can also be seen as indicative of outer results. The measures of 'place in community' imply not only better access to scarce resources, but can also denote contribution to society. Likewise, the productivity item may not only tap ability to work, but also the results of it. For this reason these items are placed in brackets in the meaning quadrant.

\section{Scheme $4 b$}

Meanings measured by Cummins' 'Comprehensive quality of life scale'

\begin{tabular}{|c|c|c|}
\hline & Outer quality & Inner quality \\
\hline \multirow{3}{*}{ Life-chances } & Income, possessions & Health \\
& Social contacts & Productivity \\
Social position & Autonomy \\
(Safety) & Opportunities & \\
\hline \multirow{2}{*}{ Life results } & & Satisfaction with: \\
& (Productivity) & Material life \\
& Social contacts \\
& & Social position \\
& Safety \\
& & Freedom \\
& & \\
\hline
\end{tabular}




\subsubsection{Example of a sociological measure of individual quality of life}

One of the first attempts to chart quality of life in a general population was the made in the Scandinavia 'Study of comparative welfare' under the direction of Erik Allardt (1976). Welfare was measured using the following criteria:

- income

- housing

- political support

- social relations

- irreplaceable

- doing interesting things

- health

- education

- life-satisfaction

Allardt classified these indicators using his, now classic distinction, between 'having', 'loving' and 'being'. This labeling was appealing at that time, because it expressed the rising conviction that welfare is more than just material wealth, and because it fitted modish notions drawn from humanistic psychology. Though it is well known, the classification has not proven to be very useful.

These indicators can also be ordered in the fourfold matrix proposed here. See scheme 4c. Most of the items belong in the left-top quadrant because they concern pre-conditions for a good life rather than good living as such, and because these chances are in the environment rather than in the individual. This is the case with income, housing, political support and social relations. Two further items also denote chances but these are internal capabilities. This is the health factor and level of education. These items are placed in the top-right quadrant of personal life-ability. The item 'irreplaceable' belongs in the utility bottom left quadrant. It denotes a value of life to others. The last two items belong in the enjoyment bottom right quadrant. 'Doing interesting things' denotes appreciation of an aspect of life ${ }^{10}$, while life-satisfaction concerns appreciation of life as a whole.

Scheme $4 c$

Meanings measured by Allardt's 'Dimensions of Welfare': having, loving, and being

\begin{tabular}{|c|c|c|}
\hline & Outer quality & Inner quality \\
\hline \multirow{2}{*}{ Life-chances } & $\begin{array}{c}\text { Income (h) } \\
\text { Housing (h) } \\
\text { Political support (h) } \\
\text { Social relations (l) }\end{array}$ & $\begin{array}{c}\text { Health (h) } \\
\text { Education (h) }\end{array}$ \\
\hline Life results & Irreplaceable (b) & $\begin{array}{c}\text { Doing interesting things (b) } \\
\text { Life-satisfaction (b) }\end{array}$ \\
\hline
\end{tabular}




\subsubsection{Example of a measure of quality of life in nations}

Lastly an illustration using measures used in cross-national comparisons of quality of life. The most commonly used indicator in this field is the 'Human Development Index'. This index was developed for the United Nations Development Program which describes the progress in all countries of the world in its annual 'Human Development Reports' (UNDP 1990). The Human Development Index is the mayor yardstick used in these reports. The basic variant of this measure involves three items; note that we deal now with scores drawn from national statistical aggregates instead of individual responses to questionnaires:

- public wealth, measured by buying power per head.

- education, as measured by literacy and schooling.

- life-expectancy at birth

Later variants of the HDI involve further items

- gender-equality measured by the so-called 'Gender empowerment index' which involves male-female ratios in literacy, school enrolment and income.

- poverty measured by prevalence of premature death, functional illiteracy and poverty

In a theoretical account of this measure the UNDP says to focus on how development enlarges people's choice, and there by their chances for leading long, healthy and creative lives (UNDP 1990: 9).

When placed in our fourfold matrix, this index can be seen to have three meanings. Firstly, it is about living conditions, in the basic variant of material affluence in society, and in the variant of social equality. These items belong in the top left quadrant. In the case of wealth it is acknowledged that this environmental merit is subject to diminishing utility, however this is not so with the equalities. Secondly, the HDI includes abilities. The education item belongs in the top right quadrant. Though a high level of education does not guarantee high mental health and pronounced ability in the art of living, it means that many citizens at least have basic knowledge. Lastly, the item 'life-expectancy' is an outcome variable and belongs in the bottom right quadrant. The bottom left quadrant remains empty. The UNDP's measure of development does not involve specific notions about the meaning of life.

The HDI is the most concise measure of quality of life in nations. Extended variants in this family provide more illustration; for instance, Naroll's (1984: 73) 'Quality of Life Index' includes contributions to science by the country, which fits the utility quadrant. The index also includes suicide rates, which belong to the appreciation quadrant.

Scheme 4d

Meanings measured by the UNDP's 'Human Development Index'

\begin{tabular}{|c|c|c|}
\hline & Outer quality & Inner quality \\
\hline \multirow{2}{*}{ Life-chances } & $\begin{array}{l}\text { Material wealth } \\
\text { Gender equality } \\
\text { Income equality }\end{array}$ & Education \\
\hline Life results & & Life-expectancy \\
\hline
\end{tabular}




\subsection{Measures for specific qualities of life}

Next to these encompassing measures of quality of life there are measures that denote specific qualities. These indicators can also be mapped on the matrix. Again some illustrative examples will suffice.

\subsubsection{Measures of livability}

Environmental life-chances are measured in two ways, by the possibilities embodied in the environment as a whole, and by relative access to these opportunities. The former measures concern the livability of societies, such as nations or cities. These indicators are typically used in developmental policy. The latter are about relative advantage or deprivation of persons in these contexts, and are rooted mostly in the politics of redistribution. These chance estimates are seldom combined.

Contents Measures of livability of society concern first nations; an illustrative example is Estes' (1984) 'Index of Social Progress'. This measure involves aspects such as wealth of the nation, peace with neighbors, internal stability and democracy. The physical habitability of the land is also acknowledged. There are similar measures for quality of life in cities (e.g. Kunz \& Siefer 1995) and regions (e.g. Korczak 1995). There are also livability counts for more or less 'total' institutions such as army bases, prisons, mental hospitals and geriatric residences.

Measures of relative deprivation focus on differences among citizens for such things as income, work and social contacts. Differences in command of these resources are typically interpreted as differential access to scarce resources (e.g. Townsend 1979).

All these measures work with points systems and summate scores based on different criteria in some way. A part of the measures is based on objective assessments and is typically derived from social statistics. Others also include self-reports about living conditions and depend for this purpose on survey data.

Limitations These inventories cannot really measure livability comprehensively. Firstly the two kinds are seldom combined; secondly both labor under serious limitations.

Limitation number one is that the topics in these inventories do not exhaustively cover environmental conditions. The indexes consist of some tens of topics that are deemed relevant and happen to be measurable. The inventories obviously lack sections on conditions we do not know of as yet. Note for example, that the list of environmental pathogens is growing each year. Further, not all the conditions we are aware of are measurable. For instance, there are no measures for highly valued qualities like 'social solidarity' and 'cultural variety'.

Problem number two is the significance of topics that are included. Since there is no complete understanding of what we really need, we can only guess at the importance of a topic. Though it is evident that we need food and shelter, it is questionable whether we need holidays and a welfare state. The choice of topics to include in a livability index is not based on evidence that we cannot thrive without something, but on the researcher's preconceptions of the good life. Elsewhere I have proposed gauging the significance of livability topics by 
their effects on health and happiness (Veenhoven 1996). The case of the welfare state can be used to illustrate that point. Several livability inventories include expenditures on social security, e.g. Naroll's (1984:73) 'Quality of Life Index'. Yet people appear not to thrive any better in nations with high social security expenditures than in comparable nations where state social security is modest (Veenhoven 2000b). Freedom appears to add more to happiness, in particular economic freedom (Veenhoven 2000c).

Problem number three is the degree of opportunities required, how many should an environment provide to be livable? With respect to food and temperature we know fairly well what amounts we need minimally and what we can use maximally. Yet, on matters of safety, schooling, freedom and wealth we know little about minimum and possible maximum needs. Lacking this knowledge, most indexes assume that more is better.

Problem number four is that the significance of opportunities is not the same for everybody, but depends on capabilities. For instance, freedom in nations appears to add to happiness only when people are well educated (Veenhoven 2000c). This means that topics should be given weights according to conditions. In practice that is hardly feasible.

Lastly there is the problem of aggregation. The aim is inclusion of all relevant opportunities, but the practice is a summing of a few topics. The assortment of topics differs considerably across inventories, and it is not clear whether one collection is better than another is. In fact each ideology of the good life can compose its own livability index.

Together this means that inclusive assessment of livability is not feasible. The best we can do is to make promising condition-profiles. Livability sum-scores make little sense.

\subsubsection{Measures of life-ability}

Capabilities for living are also measured in different ways. First there is a rich tradition of health measurement, which roots the healing professions. Second there is a trade in skill measurement, which serves selection within education and at work. Thirdly, capacities are also measured by performance at school and work.

Contents Measures of health are, for the greater part, measures of negative health. There are various inventories of afflictions and functional limitations, several of which combine physical and mental impairments. Assessments are based on functional tests, expert ratings and self-reports. The above mentioned SF-36 is an example of the latter kind of measure. In the self-report tradition general health is also measured by single questions. For an overview of these health measures see Spilker (1996). Next there are also some inventories for positive health, mainly self-report questionnaires in the tradition of personality assessment. Jahoda (1958) made the first selection of healthy traits. Verba (1988) reports a later attempt.

Measures of skillfulness concern mostly mental abilities, many of which are parts of so called 'intelligence tests'. Performance tests can be considered to be 'objective' assessment. A new offspring of this tradition is testing for 'emotional intelligence' (Mayor \& Salovy 1993) ${ }^{11}$, which is mostly a matter of 'subjective' self-reporting. Next there are numerous tests for proficiency at work and in leisure, such as laying bricks or playing cards.

Lastly, many abilities manifest in real life success. School success is measured in years schooling and by the level of schooling achieved. People who do badly at school or received no formal education in all probability lack several necessary abilities. In developing nations literacy is a common topic. Life-ability is also inferred from apparent success at work and in love. 
Limitations As in the case of livability, these measures do not provide a complete estimate of life-ability. Again the measures are seldom combined, and we meet the same fundamental limitations.

Firstly, we cannot grasp all human capabilities; there are limitations to what we can conceive and what we can measure. Possibly the current measurement repertoire misses some essential talents, in particular aptitudes required for new challenges.

Secondly, we are again uncertain about the significance of topics in the inventories. Possibly some of the things we learn in school are irrelevant. Valued positive mental health traits may actually be detrimental for coping with the problems of life. Unlike the case of livability, there is some significance testing in this field. Intelligence tests in particular are gauged by their predictive value for success at school and at work. Yet this validation criterion is not the most appropriate in this context, because success at school and work does not guarantee a happy life. Many of the other ability-tests available lack any validation.

Thirdly, it is typically unclear how much of the ability is optimal, more is not always better. As there are limitations to skill acquisition, it is the right mix that counts.

Fourthly, the functionality of abilities is contingent to the situation and fit with other traits. For instance, assertiveness is more functional in an individualistic society than in a collectivist culture, and fits better with trait-autonomy than with trait-dependence.

Lastly, we cannot adequately estimate general ability by adding up test-scores. Though psychometrists dream about a general ability factor, this seems to be a statistical epiphenomenon rather than a reality. So, also in this case we better limit to quality profiles.

\subsubsection{Measures for utility of life}

There are many criteria for evaluating the usefulness of a life, of which only a few can be quantified. When evaluating the utility of a persons life by the contribution that life makes to society one aspect could be good citizenship. That quality can be measured by criteria such as law abidance and voluntary work. I have not yet seen examples of such measures. When the utility of a life is measured with its effect on the environment, consumption is a relevant aspect. There are several measures of 'green living'. It is less easy to quantify moral value. Though it is not difficult to see that some people's lives stand out, there are no tools to rate the common man.

On some criteria we have better information at the aggregate level. Wackernagel's (1999) measure of ecological footprint indicates the degree to which citizens in a country use irreplaceable resources. Patent counts per country give an idea of the contribution to human progress and state participation in UN organizations could be seen as an equivalent of good citizenship.

Unlike the foregoing qualities of life, there have been no attempts to measure utility comprehensively. The obvious reason is that the criteria are too vague and varied. Utility is easier to conceive than measured.

Comprehensiveness is less of a problem when utility is measured subjectively. We can then assess the degree to which someone thinks of their life as useful. There are several questionnaires that measure subjective sense of meaning. Chamberlain and Zika 1988 review some of these). These questionnaires do not measure actual usefulness of life, but rather the person's satisfaction with his perception of the matter. Though these feelings may have some reality basis, the measures say more about the subjective appreciation of life; because the utility of ones life is so difficult to grasp, judgment is easily overshadowed by how much one likes or dislikes life ${ }^{12}$. 


\subsubsection{Measures of appreciation of life}

It is easier to measure the subjective appraisal of life. Since this is something people have in mind, we can simply ask them ${ }^{13}$. Interrogation is mostly done by direct questioning via an interview or a written questionnaire. Since the focus is on 'how much' the respondent enjoys life rather than 'why', the use of qualitative interview methods is limited in this field. Most assessments are self-reports in response to standard questions with fixed response options. As well as numerous single items, there are various questionnaires. Incidentally, subjective wellbeing is assessed by less obtrusive methods, such as analysis of diaries and projective tests.

Contents Many of these measures concern specific appraisals such as satisfaction with ones sex life or perceived meaning of life. As in the case of life-chances, these aspects cannot be meaningfully added in a whole, firstly because satisfactions cannot be assessed exhaustively and secondly because satisfactions differ in significance. Yet humans are also capable of overall appraisals. As noted earlier, we can estimate how well we feel generally and report on that. So, encompassive measurement is possible in this quality quadrant.

There are various ways to ask people how much they enjoy their life-as-a-whole. One way is to ask them repeatedly how much they enjoy it right now, and to average the responses. This is called 'experience sampling'. This method has many advantages, but is quite expensive. The other way is to ask respondents to estimate how well they feel generally or to strike the balance of their life. Almost all the questions ever used for this purpose are stored in the 'Catalog of Happiness Measures', which is part of my 'World Database of Happiness' (Veenhoven 2000a).

Questions on enjoyment of life typically concern the current time. Most questions refer to happiness 'these days' or 'over the last year'. Obviously the good life requires more than this, hence happiness must also be assessed over longer periods. In several contexts we must know happiness over a lifetime, or better, how long people live happily. Remember the above discussion of this criterion in the context of biology and system theory.

At the individual level it is mostly difficult to asses how long and happy people live, because we know only when they are dead; however, at the population level the average number of years lived happily can be estimated by combining average happiness with lifeexpectancy. For details of this method see Veenhoven (1996).

Limitations? There are doubts about the value of these self-reports, in particular about interpretation of questions, honesty of answers and interpersonal comparability. Empirical studies, however, show reasonable validity and reliability, for the details see Veenhoven (1996:19-22, 1998) and Schyns (in preparation).

There are also qualms about comparability of average response across cultures, and hence about the above-mentioned estimate of happy years of life. It is claimed that questions are differently understood and that response bias differs systematically in countries. These objections have also been checked empirically and appeared not to car any weight. Many of these checks are reported in Veenhoven (1993).

In this case there is no problem of summation, the answer to the question about appreciation of life-as-a-whole suffices. 
Scheme 5

Inclusive measures for specific qualities of life

\begin{tabular}{|c|c|c|}
\hline \multirow{2}{*}{ Life-chances } & Outer quality & Inner quality \\
\hline & $\begin{array}{c}\text { Quality of society } \\
\text { Livability scores } \\
\text { Position within society } \\
\text { Deprivation indexes }\end{array}$ & $\begin{array}{c}\text { Impairment indexes } \\
\text { Positive health inventories } \\
\text { Capability tests } \\
\text { Educational grades }\end{array}$ \\
\hline & $?$ & $\begin{array}{c}\text { Satisfaction summations } \\
\text { Self-ratings of happiness } \\
\text { Happy life-years }\end{array}$ \\
\hline
\end{tabular}

\section{CAN QUALITY OF LIFE BE MEASURED INCLUSIVELY?}

As noted in the introduction, terms like 'quality-of-life' and 'wellbeing' were circulated to denote overall worth of life. Hence the introduction of these terms was followed by attempts to measure the goodness of life comprehensively. We have considered the meanings addressed by these inventories in section 2.1. All assess overall quality of life by summing different merits and in these summations the qualities discerned are merged. This adding of apples and pears yields a great variety of fruit salads, each with their special flavor and devotees. Unfortunately this trade makes little sense.

Why cross-quadrant sum-scores make no sense

Firstly, three of the four separate qualities in my scheme cannot be measured comprehensively. Above I have argued that exhaustive assessment is not possible in the cases of livability, life-ability and utility of life. Only happiness can be measured completely, because it is an overall judgment in itself. Where most of the components are incomplete, the sum cannot be complete either. Hence, sum-scores are always selective, and therefore say more about $a$ good life than about the good life.

Secondly, one cannot meaningfully add 'chances' and 'outcomes'. A happy and productive life is no better when lived in a perfect environment by an well-endowed person, than when realized in difficult circumstances by someone handicapped.

Thirdly, sum-scores fail to appreciate the functional relationships between the qualities of life discerned. The value of environmental opportunities depends on personal capacities. An orchestra may be well equipped with violins, but if its members are horn players the musical performance will still be poor. Likewise, the worth of life-abilities depends on the environmental challenges for which they are needed. It is their fit that counts, 
rather than the mere amounts.

These contingencies are acknowledged in some concepts, for instance, Gerson (1976) defines quality-of-life as harmony of self-interest and 'transcendent' utility. Yet this is easier said than measured. Firstly, such harmony can hardly be quantified, for instance, the fit of individual and environmental potentialities cannot be observed as such, at best we can infer fit from resulting enjoyment of life. Secondly, there is mostly not one best fit, but several fitting configurations, for example collectivist and individualistic arrangements can be equally harmonious but still represent quite different qualities.

The above problems could partly be met if one restricted to the few conditions and capabilities of which the mutual fit can be estimated, for instance if we focus on sheer material subsistence. This is close to the 'basic needs approach', which is said to have formed the basis of the Human Development Index (UNPD 1990). Yet the HDI does not really solve the problem either.

\section{Why there is most in happiness}

When human capacities fit environmental demands, there is a good chance that human needs are gratified. Only bad luck or willful deprivation can block that outcome. Gratification of basic needs will manifest in a stream of pleasant experiences. Biologically this is a signal that we are in the 'right pond'. In human consciousness this manifests in good mood, and subsequently in satisfaction with life as a whole.

So, happiness is both a merit in itself, and indicative of good life-chances. Subjective happiness implies two things: Firstly that the minimal conditions for humans thriving are apparently met, secondly that the fit between opportunities and capacities must be sufficient. Hence happiness says more about the quality of life-chances that the sum-scores do.

This means that at least three of the four qualities of life can be meaningfully summarized by the degree and duration of happiness. This is how the good life is characterized in the closing sentence of many fairy tales: "They lived long and happily".

\section{Why happiness is not all}

The proposed fourfold matrix visualizes the main limitation of that view, ignoring the utility quadrant. As noted above, a life can be happy but not useful or useful but not happy. Though these qualities often go together, they do not necessarily so.

\section{DISCUSSION}

\section{Use of this taxonomy}

This exercise started with a discussion of the confusion surrounding words for 'the good life'. As a remedy I proposed a fourfold matrix classification of the qualities of life. This taxonomy was used to clarify the substantive meanings denoted by current words and measures. This worked, though it was often not possible to place current notions in one particular quadrant. One can see this as a weakness, i.e. the scheme does not fit current concepts, or as strength, it denotes new meanings.

Now there are more classifications of quality of life, which are also used to structure this complex field. In section 2.3 we have reviewed a few. Is this one any better? It would be too much to review all the alternative classifications. Let it suffice to note that the mayor distinctions in the field are between 'objective' and 'subjective' qualities and along 
disciplinary kinds; e.g. economic, social and psychological wellbeing. A great advantage of the proposed fourfold matrix is that it makes more sense theoretically. The distinction between 'chances' and 'results' positions the merits in a functional perspective, the distinction between 'livability' and 'life-ability' brings the contingencies to mind. As such, this taxonomy helps us to see that overall quality of life cannot be seen as summed merits, but must rather be conceived as merit-configurations.

\section{Elusive utilities}

In this taxonomy the 'utility' quadrant is the most problematic. The criteria are quite diverse and elusive. One can see use in anything. Contrary to happiness there is no link with demands of human nature. The matter is in fact unmeasurable.

In an earlier paper on this subject I therefore left the category out. This left me with a simpler three-step scheme of 1) livability, 2) life-ability and 3) life appreciation. (Veenhoven 1999). This is in line with the utilitarian idea that the ultimate value is in the greatest happiness of the greatest number. Bentham will nod in his glass case.

Though clear cut, that 3-step scheme misses an important class of qualities. That is, the values that override sheer functionality and enjoyment. It is not possible to weave these meanings in as contributions to the happiness of other people, because many of them have no effect on happiness. The best I can do is acknowledge the existence of these many qualities, and mark the morass on my map. Without forewarning we get stuck in it over and over again.

\section{Significance of happiness}

I concluded that the most comprehensive measure for quality of life is how long and happy a person lives. Though happiness was not proclaimed as the only quality criterion, it was presented as the best available summary indicator. Note that this is not a statement of belief, but a conclusion based on assumptions about the nature of happiness.

I acknowledge that subjective appreciation of life is not all, because happiness does not guarantee that other possible values are met. That latter position must be nuanced in two ways: both in favor and against.

The favorable nuance is that happiness and utility do go together quite often. Both outcomes draw on the same opportunities. Useful living also requires tolerable environmental conditions and fair individual capabilities, in many cases similar ones to happiness. Further, objective utility is at least partly reflected in subjective awareness, and as such is part of the appraisal of life as-a-whole ${ }^{14}$.

In contrast, subjective enjoyment of life is not always appropriate in the given conditions. Though happiness works as a compass, it is not always an infallible tool for orientation. I do not deny that happiness results sometimes from cognitive distortion or chemical intoxication. Still, this is the exception rather than the rule, and in the long run dysfunctional happiness will destroy itself. So this problem applies more to short term happiness than to happy life years.

\section{Guide for research}

The taxonomy does more than just map different qualities of life. It can also be used to help explore their interrelations. The first step is to distinguish qualities of life as different phenomena; the next steps will be to chart causal effects. As such the scheme suggests interesting research lines. One thing we can determine is those conditions for happiness that also promise desirable external effects. Since there are probably more ways to happiness, we can then select the most 'useful' one. 


\section{CONCLUSION}

One cannot meaningfully speak about 'quality of life' at large. It makes more sense to distinguish four qualities: 1) livability of the environment, 2) life-ability of the person, 3) utility of life for the environment, and 4) appreciation of life by the person. These qualities cannot be added, hence sum-scores make little sense. The best available summary indicator is how long and happily a person lives.

of healthcare the term 'quality of life' emerged to convey the idea that there is more than mere quantity of survival time. Likewise, the word 'wellbeing' came into use in contrast to sheer economic 'welfare' 


\section{REFERENCES}

Allardt, E. (1976)

Dimensions of welfare in a comparative Scandinavian study

Acta Sociologica, vol. 19, pp. 227-239

Andrews, F. \& Withey, S (1976)

Social indicators of wellbeing: American perceptions of quality of life.

Plenum Press, New York

Bar-On, R. (1997)

BarOn Emotional Quotient Inventory: a measure of emotional intelligence

Multi-Health Systems Inc, Toronto, Canada

Bentham, J. (1789)

An introduction into the principles of morals and legislation

Bernheim, J.L. \& Buyse, M. (1983)

The anamnestic comparative self-assessment for measuring subjective quality of life for cancer patients.

Journal of psycho-social oncology vol. 1, pp. 25-38

Brock, D.W. (1993)

Life and death: Philosophical essays in biomedical ethics

Cambridge University Press, New York

Chamberlain, K. \& Zika, S. (1988)

Measuring meaning in life, examination of three scales

Journal of Personal and Individual Differences, vol. 9, pp.589-596

Colby, B.N. (1987)

Well-being: a theoretical program

American Anthropologist, vol. 87, pp. 874-895

Cummins, R.A. (1993)

Comprehensive Quality of Life Scale for adults. Manual ComQol-A4

Deakin University, School of Psychology, Australia

Cummins, R.A. (1997)

Dictionary of instruments to measure Quality of Life and cognate areas.

Deakin University, School of Psychology, Australia

Diener, E. (1984)

Subjective wellbeing

Psychological Bulletin, vol. 95, pp. 542-575 
Estes, R. (1984)

The social progress of nations

Preager, New York, USA

Fernandez-Ballesteros, R. (1996)

Quality of life: concept and assessment

Paper presented at the 26th international congress of psychology, Montreal

Frankl, V. (1946)

Man's search for meaning, an introduction to logo-therapy

Beacon Press, Boston, USA

Gerson, E.M. (1976)

On quality of life

American Sociological Review, vol. 41, pp. 793-806

Jahoda, M. (1958)

Current concepts of positive mental health

Basic books, New York, USA

Jolles, H.N. \& Stalpers, J.A. (1978)

Welzijnsbeleid en sociale wetenschappen

Deventer

Korczak, D (1995)

Lebensqualität Atlas

Westdeutscher Verlag, Germany

Kunz, M. \& Siefer, W (1995)

Wo Sie am besten leben

FOCUS, Lebensqualitätatlas, Available: www.genios.de/cgi-bin

Lane, R.E. (1994)

Quality of life and quality of persons. A new role for government?

Political theory, vol. 22, pp. 219-252

Mayer, J.D. \& Salovy, P. (1993)

The intelligence of emotional intelligence

Intelligence, vol. 17, pp. 433-442

McCall, S. (1975)

Quality of life

Social Indicators Research, vol. 2, pp. 299-249

Michalos, A. (1985)

Multiple Discrepancy Theory (MDT)

Social Indicators Research, vol. 16, pp.347-413 
Mill. J.S. (1863)

Utilitarianism

20th impression by Fontana Press 1990

Musschenga, A.W. (1994)

Quality of life of handicapped people

In: L. Nordenfelt (ed.) 'Concepts and measurement of quality of health care', Kluwer

Academie publishers, Dordrecht. pp.181-198.

Narroll, R. (1983)

The moral order. An introduction to the human situation

Sage

Noll, H-H. (1999)

Konzepte der Wohlfahrtsentwicklung: Lebensqualitat und 'neue' WohlfahrtsKonzepte.

Euro-reporting paper nr 3, ZUMA, Mannheim, Germany

Nordenfelt, L. (1989)

Quality of life and happiness

In: Bjork, S. \& Vang, J. (Eds) 'Assessing quality of life', Health service studies nr 1, Samhall, Klintland, Sweden

Ouelette-Kuntz, H (1990)

A pilot study in the use of the Quality Of Life Interview Schedule

Social Indicators Research, vol. 23, pp. 283-298

Sandoe, P. (1999)

Quality of life, three competing views

Ethical theory and Moral Practice, vol. 2, pp. 11-23

Schyns, P.

Subjective wellbeing: concepts, measurability and cross-national comparability

In preparation

Sen, A: (1992)

Capability and wellbeing

In: Sen, A. \& Nussbaum, M (Eds) 'The quality of life'

Clarendon Press, Oxford, UK, pp. 30-53

Spilker, B. (Ed) (1996)

Quality of Life and Pharmaco-economics in Clinical Trials

Leppincott-Raven Publishers, Philadelphia USA

Spitzer, W.O., Dobson, A.J., Hall, J., Chesterman, E., Levi, J. \& Shepherd, R. (1981)

Measuring the quality of life of cancer patients

Journal of Chronical Disease. Vol. 34, pp. 585-597

Tatarkiewicz, W. (1975)

Analysis of happiness

Martinus Nijhoff, The Hague, Netherlands 
Terhune, K.W. (1973)

Probing policy relevant questions on the quality of life

In: 'The quality of life concept' Environmental protection agency, Washington, USA

Townsend, P. (1979)

Poverty in the UK: a survey of household resources and standards of living

Penguin, Hammondsworth, UK

United Nations Development Program (UNDP) $(1990,1998)$

Human Development Report 1990

Oxford University Press, New York

Veenhoven, R. (1984)

Conditions of happiness

Kluwer, Dordrecht, Netherlands

Veenhoven, R. (1988)

The utility of happiness

Social Indicators Research, vol. 20, pp. 333-354

Veenhoven, R. (1993)

Happiness in Nations

RISBO, Rotterdam. The Netherlands.

Veenhoven, R. (1996)

Happy life-expectancy

Social Indicators Research, vol.39, pp. 1-58

Veenhoven, R. (1997)

Progres dans la comprehension du bonheur

Revue Quebecoise de Psychologie, vol 18, pp 29-74

Available in English 'Advances in the understanding of happiness'

Veenhoven, R. (1998)

Vergelijken van geluk in landen

Sociale wetenschappen, vol. 42, pp. 58-84

Veenhoven, R. (1999)

Quality of life and happiness, not quite the same

In: DeGirolamo, G. (Ed) 'Health and quality of life'

Il Pensierro Scientifico, Rome, in press

Veenhoven, R. (2000)

Catalog of Happiness Measures

World Database of Happiness 
Veenhoven, R. (2000b)

Wellbeing in the welfare state: level not higher, distribution not more equitable.

Journal of Comparative Policy Analysis (in press)

Veenhoven, R. (2000a)

Happiness and freedom

In: Diener, E. \& Suh, E. (Eds) 'Subjective wellbeing across cultures'

MIT-press, Boston USA (in press)

Verba, S.K. (1988)

Measurement of positive mental health, some theoretical and practical considerations

International Journal of Clinical Psychology, vol. 15, pp. 6-11

Wackernagel, M. et al. (1999)

National natural capital accounting with the ecological footprint concept

Ecological economics, vol. 29, pp. 375-390

Ware, J.E. Jr (1996)

The SF-36 Health Survey

In: B. Spilker (Ed) 'Quality of Life and Pharmaco-economics in Clinical Trials'

Leppincott-Raven Publishers, Philadelphia USA, 1996, pp337-345

Wentholt, R. (1975)

Map motivatieleer

Erasmus University Rotterdam

Zajonc, R.B. (1980)

Feeling and thinking: preference needs no inference

American Psychologist, vol. 35, pp.151-175

Zapf, W. (1984)

Individuelle Wohlfahrt: Lebensbedingungen und wahrgenommene Lebensqualität In: Glatzer, W. \& Zapf, W. (Eds) 'Lebensqualität in der Bundesrepublik. Objective Lebensbedingungen und subjectives Wohlbefinden, Campus Verlag, Frankfurt am Main, pp. $13-26$ 


\section{NOTES}

1 The World Health Organization defines health as "a state of complete physical, mental and social wellbeing".

2 In the Netherlands in the 1970's, the 'limits to growth'movement used the slogan 'not welfare, but wellbeing' (In Dutch: Geen welvaart maar welzijn). In this context, the capriciousness of the term is emphasized.

Interestingly, the term was soon taken over by social workers, who came to call their services 'wellbeing work' . Hereby, the term wellbeing came to denote a very limited meaning, in fact far more limited than economic welfare, which denotes all goods and services produced in society. Still the suggestion of encompassivenes remained, much to the pleasure of the profession.

3 For an overview of the various definitions of 'quality of life' see: Fernandes-Ballesteros (1996). A review of definitions of happiness can be found with Veenhoven (1984: 16-17)

4 In sociology, the term 'life-chances' is used in the more limited meaning of 'environmental opportunities', here called 'livability, and in that context mostly for a set of social opportunities, access to scarce resources.

5 There are three main meanings or health: The maxi variant is all the good (WHO definition), the medium variant is lifeability, and the mini-variant is absence of physical defect.

6 A problem with this name is that the utilitarians used the word utility for subjective appreciation of life, the sum of pleasures and pains.

7 Frankl's (1946) logo-therapy aims to make people believe in sense they do not see.

8 This quality-of-life is the subject of the Journal of happiness Studies

9 This analogy fits to the extent that the profit of a firm also reflects the degree to which functional demands for the business are met. Yet unlike functional needs for human functioning these demands are not fixed genetically and nor are they linked so close to affect like signals.

10 'Doing interesting things' can also be seen as a quality in itself, especially when the person does not like it. In this interpretation this item should be placed in the meaning quadrant, because it represents some kind of perfection.

11 The well known Bar-on (1997) EQ-tests measures positive mental health.

12 This is commonly referred to as the top-down' effect in evaluations of life. See e.g. Diener (1984)

13 Subjective wellbeing is also inferred from non-verbal cues, such as smiling, and from signs of despair such as suicide and excessive risk taking. Unfortunately, these 'objective' indicators appear to fit subjective feeling rather badly. Physical measures are not available; the 'hedometer' still waits for invention.

14 The effect of perceived meaningfulness on happiness will be particularly great if there is an innate need for meaning fulness. Some scholars believe so, but others see the search for meaning rather as an 'unintended' byproduct of human consciousness, which is not strongly linked to hedonic experience (cf. Wentholt 1975). 